\title{
Étienne Hofmann, François Rosset, Le Groupe de Coppet. Une constellation d'intellectuels européens
}

\section{Paola Martinuzzi}

\section{(2) OpenEdition}

1 Journals

\section{Edizione digitale}

URL: https://journals.openedition.org/studifrancesi/46014

DOI: 10.4000/studifrancesi.46014

ISSN: 2421-5856

\section{Editore}

Rosenberg \& Sellier

\section{Edizione cartacea}

Data di pubblicazione: 1 octobre 2007

Paginazione: 459-460

ISSN: 0039-2944

\section{Notizia bibliografica digitale}

Paola Martinuzzi, «Étienne Hofmann, François Rosset, Le Groupe de Coppet. Une constellation d'intellectuels européens», Studi Francesi [Online], 152 (LI | II) | 2007, online dal 30 novembre 2015, consultato il 24 novembre 2021. URL: http://journals.openedition.org/studifrancesi/46014; DOI: https://doi.org/10.4000/studifrancesi.46014

Questo documento è stato generato automaticamente il 24 novembre 2021.

\section{(c) $(1) \odot$}

Studi Francesi è distribuita con Licenza Creative Commons Attribuzione - Non commerciale - Non opere derivate 4.0 Internazionale. 


\title{
Étienne Hofmann, François Rosset, Le Groupe de Coppet. Une constellation d'intellectuels européens
}

\author{
Paola Martinuzzi
}

\section{NOTIZIA}

ÉTIENNE HOFMANN, FRANÇOIS ROSSET, Le Groupe de Coppet. Une constellation d'intellectuels européens, Lausanne, Presses polytechniques et universitaires romandes, «Le savoir suisse», 2005, pp. 143.

1 Il libro pone in causa, in modo sinteticamente utile all'approccio culturale, una vasta gamma di temi, di ordine letterario, etico politico, storico, filosofico, estetico, religioso, che fanno luce sul cenacolo intellettuale staëliano, delineandone l'importanza e la funzione culturale europea.

Una affinità di ordine ideologico, che nulla sottrasse alla individualità dei singoli componenti, non autodefinitisi come "gruppo", strinse attorno a Germaine de Staël, per un quindicennio, tra il 1803 e il 1817, pensatori e scrittori di rilievo, e ciò avvenne nella rousseauiana svizzera, a Coppet, divenuta dimora di esilio, antitesi della Parigi napoleonica. La scelta di stabilire una continuità storica fra passato e avvenire, compromessa dalla frattura rivoluzionaria, il confronto fra moderno e antico, come ripresa di una secolare querelle, rinverdita nel moderno confronto fra latinità e germanesimo, fanno del tradizionale spirito conservatore e dell'honnêteté del nucleo svizzero, il punto centrale e precorritore di un rinnovamento evolutivo della sensibilità. Al moderno itinerario di una nuova cultura sarà rivolta l'opera dei componenti del gruppo, per tutto l'Ottocento, anche dopo la morte ai Madame de Staël.

Il processo di "accelerazione della storia" dato dalla rivoluzione del 1789 pose fine, come è noto, all'Ancien Régime, ma non approdò alla formazione di una repubblica; era subentrata una nuova forma di dispotismo, il cesarismo napoleonico, che ridimensionò 
la carta dell'Europa. Il «Discorso alla nazione tedesca» di Fichte, del 1807, e l'insorgenza del sentimento nazionale, nella crisi dell'universalismo settecentesco, furono la incisiva risposta, in questo momento storico. Nel gruppo di Coppet, il primo a percepire apertamente i lineamenti del dispotismo fu Benjamin Constant, radiato dal Tribunato nel 1802. A Constant il libro dedica più pagine.

Ma le origini del gruppo di Coppet sono più remote. Una "prima generazione", con Grimm, de Suard, de Meister, si ebbe intorno alla figura di Jacques Necker e nel salotto parigino di Suzanne Necker che accolse scrittori famosi dell'illuminismo: Diderot, d'Alembert, Marmontel; ad essi fecero seguito, a Coppet, con Madame de Staël, insigni protagonisti della nuova cultura: August von Schlegel, Villiers, Jean de Müller, Sismondi. Residenza ospitale, non lussuosa, Coppet coltivò il gusto della parola anche animando una propria vitalità teatrale, che rimase implicata nel rinnovamento del teatro europeo. Coppet forniva interpreti e autori, nella figura stessa di Mme de Staël e dei suoi ospiti, aprendo il suo spazio alla scena europea, con forme moderne, anticipatrici del comparativismo. Furono notevoli, in questo campo, le opere teoriche, elaborate con spirito innovatore, ma sempre attente alla tradizione. Importanti documenti del rinnovamento teatrale restano De l'Allemagne e De Vesprit des traductions (1816) di Mme de Staël, il Cours de littérature dramatique (1814) di Schlegel, gli scritti di Wilhelm von Huboldt, le pagine del trattato De la littérature (1813) di Sismondi, la prefazione di Renjamin Constant al suo adattamento del Wallenstein (1809) di Schiller.

«Inépuisable foyer de la parole», Coppet, come la Weimar di Goethe o la Zurigo di Henri Meister, fu luogo di un internazionale scambio di "lettere". Sempre nello spirito dell'equilibrio fra i due poli, del moderno e dell'antico, eredi dell'engagement culturale di Voltaire, i componenti del gruppo optano per la funzione sociale della letteratura, senza escludere una valutazione critica di questo percorso. Notevole in questo campo, De la Littérature considérée dans les rapports avec les institutions sociales di Madame de Staël, tappa fondamentale della evoluzione del pensiero estetico. Pur rimanendo scrittori engagés, i componenti del gruppo si rivolsero al gusto e alla necessità di una scrittura intima, approdo dei sentimenti, in una direzione diversa dal romanzo filosofico di Voltaire. Delphine, Corinne di Mme de Staël e Adolphe di Benjamin Constant sono documenti di questa esigenza che mette a confronto la sfera pubblica e quella privata.

Molto presente a Coppet è l'écriture du moi, dopo i modelli dei Mémoires di Saint-Simon e delle Confessions di Rousseau. Si tratta di una scrittura personale «au milieu du monde» (p. 58). Ne aveva dato testimonianza Mme de Staël nel suo Dix Années d'exil. Ma l'esperienza di una scrittura esclusivamente intima, come avrebbe potuto essere Mon Journal (1785) non è stata, da Mme de Staël, portata a compimento. La stessa cosa si può dire dei Journaux intimes di Benjamin Constant, opera tenuta segreta e apparsa solo nel 1887.

Una delle forme della scrittura dell'io è l'écriture du voyage. Gli appunti di viaggio di Mme de Staël sono confluiti in De l'Allemagne e in Corinne. Il gruppo di Coppet è consapevole che non si può più viaggiare come alla fine del Settecento, quando $i$ philosophes erano protetti dalle loro certezze. C'è ora inquietudine, interiorità, soggettività e l'eredità dei Lumi è assunta in modo critico; Coppet prende le sue distanze dal cosmopolitismo, così come era stato interpretato dagli scrittori del Settecento. C'è il sogno di un'altra Europa, dove l'apporto delle nazioni non contempla l'egemonia francese né il materialismo ateistico. Coppet rifiuta anche l'utilitarismo settecentesco e usa con parsimonia il sensismo di Condillac; prende corpo invece 
l'influenza dell'idealismo tedesco. Molto diverso, dunque, il salotto di Mme de Staël a Coppet dagli ultimi salotti legati all'Encyclopédie: quello di Mme Helvétius o di Mme de Condorcet. È fondamentale, nei pensatori di Coppet, il senso della continuità storica; Mme de Staël e Benjamin Constant l'avevano appreso, partendo dall'idea di "perfettibilità" in J.-J. Rousseau. De la Littérature (1800) applica questo principio non solo alle scienze, ma alle lettere, dove è importante la perfettibilità della forma, e la necessità di adeguare modernamente alla evoluzione del tempo il percorso della letteratura. Questa sensibilità ha creato un nuovo atteggiamento nei confronti del Medioevo, pensiero approfondito da Schlegel, ospite di Coppet. Il concetto di perfettibilità investe anche lo spazio interiore e conduce alla necessità del pensiero religioso, anche se Coppet è poco dogmatica ed eterogenea nei suoi orientamenti di fede.

8 Coppet privilegia una unione delle differenze nella visione di una nuova Europa intesa come sistema di valori, e ciò va oltre il cosmopolitismo internazionalista dei Lumi. 